\title{
Serial correlation and TEV bias in index funds
}

\author{
H. Raubenheimer \\ Sanlam Investment Management*, Private Bag X8, \\ Tygervalley 7536, Republic of South Africa \\ heidir@sim.sanlam.com
}

Received April 2003

\begin{abstract}
Index or passive fund managers and investors analyse the interim volatility of the difference between their fund's returns and the index's returns, i.e. the fund's tracking error variance** (TEV) in order to monitor the success with which tracker funds mimic their benchmark. The objective of a passive or index fund manager should be to keep TEV as close to zero as possible. Pope and Yadav (1994) show that an index fund that is overweight relative to it's index in either relatively less or relatively more liquid stocks, is expected to exhibit negative serial correlation in its TE's. Consequently, estimates of TEV will be upwardly biased, particularly when using high frequency (such as daily or weekly) data.
\end{abstract}

This article finds evidence of negative serial correlation in the weekly, monthly and quarterly TE's of domestic index funds. Consequently it is shown that TEV will likely be overestimated. There are two important implications of this upward bias in TEV estimation. Firstly, index funds, which are expected to offer close to zero benchmark-relative or active risk, may appear far more 'risky' than they actually are thus damaging their value-proposition to investors. Secondly, when funds appear to have greater TEV than they actually do, the manager may 'churn' the fund's assets more than necessary in order to bring the fund back into alignment with its index thus incurring greater and unnecessary transaction costs.

The analyses in this article therefore suggest that TE measurements should be examined for negative serial correlation before estimates of TEV are made. If serial correlation is detected, estimates of TEV should either be made from lower frequency, uncorrelated TE measurements, if they are available, or an adjustment technique such as the Lo-MacKinlay adjustment should be applied to correct for the bias in TEV estimation.

*The views of the writer do not necessarily reflect those of Sanlam Investment Management. This article should not be construed as financial advice from Sanlam Investment Management. Professional advice should be sought before any action is taken based on this article. Sanlam Investment Management disclaims any responsibility for any action taken based on this article.

**Tracking error, in the context of this article, is intended to mean the return of the fund in excess of the return of the index in the same period. Tracking error variance (TEV) is thus the variance of these relative returns.

\section{Introduction}

The Unit Trust ${ }^{1)}$ industry started in South Africa in 1965 and provided individuals with a vehicle with which to invest in a diverse, professionally managed investment portfolio. This industry has proved very popular and has expanded from only eight funds in 1980 to 409 publicly listed funds and 172 billion Rand under management. With growing cynicism concerning the success and the cost of active portfolio management ${ }^{2}$, index or so-called 'passive' funds have gained popularity. The number of domestic listed index funds grew from four funds in 1996 to thirteen funds and 2.5 billion Rand under management. Furthermore the JSE Securities Exchange recently launched South Africa's

\footnotetext{
${ }^{1)}$ Mutual Fund

${ }^{2)}$ Refer to Admati and Pfleiderer (1997) for an analysis of the success of benchmark adjusted management fees.
}

first exchange traded index trackers (SATRIX) ${ }^{3)}$, starting with one fund in the latter part of 2000 and launching two more in 2002.

The successful management of index funds relies on constant re-balancing to bring their constituent parts in line with the index that they track. However, practical constraints such as cash flows ${ }^{4)}$, transaction costs, liquidity differences among stocks and short-term market inefficiency can inhibit a fund manager's ability to perfectly track an inde ${ }^{5}$. In order to monitor the success with which tracker

\footnotetext{
${ }^{3)}$ The SATRIX funds are listed instruments on the Johannesburg Stock Exchange which track the performance of the ALSI 40, FINI 15 and INDI 25 - see www.satrix.co.za

${ }^{4)}$ Refer to Connor (1995) for a comprehensive discussion on overcoming cash flow difficulties in index fund management.

${ }^{5)}$ Refer to Worzel et al (1994) for an approach to overcome these difficulties in fixed income index fund management.
} 
funds mimic their benchmarks, managers and investors analyse the interim volatility of the difference between their fund's returns and the index's returns, i.e. the fund's tracking error variance ${ }^{6}$ (TEV). TEV (or its square root, TE Standard Deviation) is termed 'active risk' (refer to Grinold \& Kahn (2000)) because it attempts to measure the extent of a fund returns' departure from the benchmark as a consequence of active management. Thus the objective of a passive or index fund manager should be to keep TEV as close to zero as possible.

Pope and Yadav (1994) show that an index fund that is overweight relative to its index in either relatively less or relatively more liquid stocks, is expected to exhibit negative serial correlation in its TE's. Consequently, the usual estimate of TEV will be upwardly biased. That is:

$$
\frac{\sum_{\mathrm{t}=1}^{\mathrm{T}}\left(\mathrm{TE}_{\mathrm{t}}-(\overline{\mathrm{TE}})\right)^{2}}{\mathrm{~T}-1} \geq \operatorname{Var}[\mathrm{TE}]
$$

where the left-hand side of (1) is the sample estimate of variance; the right hand side is the population variance or TEV; $\mathrm{TE}_{\mathrm{t}}$ are the TE's at time $t$ of the fund against the index and $\mathrm{T}$ is the total number of time periods over which the variance of TE's was estimated. Furthermore, Pope and Yadav (1994) expect the bias to be greater when TEV is estimated over higher frequency data.

There are two important implications of serial correlation in TE's for monitoring the performance of index funds. Firstly, index funds as a whole are intended to offer much less (theoretically zero) benchmark-relative risk than actively managed funds. The bias in TEV estimation can thus be damaging to the passive fund industry as a whole by making passive funds appear more 'risky' or actively managed than they actually are. This can potentially damage the value-proposition of passive manage-ment and lead to unfairly punishing passive fund managers. Secondly, when funds appear to have greater TEV than they actually do, the estimation error may lead to greater 'churn' or turnover in the fund's assets than necessary to bring the fund back into alignment with its index thus incurring greater and unnecessary transaction costs.

The first section of this article explores the rationale behind the expectation of serial correlation and biased TEV estimation. The second section applies this rationale to the South African Unit Trust environment and index tracking funds in particular. In this second section, evidence for negative serial correlation is sought over various TE frequencies (weekly, monthly and quarterly). The third section of the paper describes a possible correction for the TEV bias, the Lo-MacKinlay ${ }^{7}$ adjustment, and measures the effect of this adjustment on the estimation of TEV for domestic tracker funds. The conclusion follows.

\footnotetext{
${ }^{6}$ This article adopts the same terminology as Roll (1992) in that Tracking error is intended to mean the return of the fund in excess of the return of the index in the same period. Tracking error variance (TEV) is thus the variance of these relative returns.
}

\section{The rationale behind TEV bias}

Pope and Yadav (1994) argue that an index fund that is overweight in either relatively less or relatively more liquid stocks is expected to exhibit negative serial correlation (and consequently negative serial covariance) in its excess-ofbenchmark returns (TE's):

$\operatorname{Cov}\left[\mathrm{TE}_{\mathrm{t}}, \mathrm{TE}_{\mathrm{t}-\mathrm{k}}\right]<0$ for $\mathrm{k}>0$

where $\mathrm{TE}_{\mathrm{t}}$ and $\mathrm{TE}_{\mathrm{t}-\mathrm{k}}$ are the excess-of-benchmark returns of an index fund over an estimation period, $t$, and a lagged period, $\mathrm{t}-\mathrm{k}$, of the same duration.

In order for the measurement of TEV of a fund over a particular time period (i.e. the sample variance as expressed by the left hand side of (1)) to be an unbiased estimate for the true active risk of the fund (i.e. the population variance as expressed by the right hand side of (1)), the fund's TE's over this period (i.e. the elements of the sample) must be independent and identically distributed. If the fund's TE's are negatively serially correlated, then the usual measurement (1) of the fund's TEV will be biased upwards. That is, the estimated active risk of the fund will be higher than the fund's true active risk.

The expectation of negative serial correlation in TE's is based on the following argument. Less liquid stocks are expected to be less price efficient than more liquid stocks i.e. the adjustment of the price of less liquid stocks to new information is slower than the adjustment of the price of more liquid stocks to the same information. Thus the covariance between the return on a less liquid stock with the lagged return on a more liquid stock (the cross-covariance) is expected to be positive i.e. the price on the less liquid stock in a subsequent period is expected to move in the same direction as the price of the more liquid stock in a prior period.

This cross-covariance can be written as follows:

$$
\operatorname{Cov}\left[\mathrm{R}_{\text {(lessliquid)t }}, \mathrm{R}_{\text {(moreliquid)t } \mathrm{t} \mathrm{k}}\right\rfloor>0 \text { for } \mathrm{k}>0
$$

where $\mathbf{R}_{\text {(lessliquid) }}$ and $\mathbf{R}_{\text {(moreliquid) }}$ are the returns on less liquid and more liquid stocks respectively over an estimation period, $t$, and a lagged period, $t-k$, of the same duration.

Based on the expectation that markets show less efficiency in the short term and greater efficiency in the long term, the cross-covariances in (3) across stocks is expected to be increasingly positive, as the frequency of returns increases. That is, the cross-covariance of weekly return data across all the stocks in question is expected to be greater than the cross-covariance of monthly return data because, the higher the frequency of price information examined, the more evidence of price-inefficiency we are likely to find. This evidence accumulates over the estimation period, increasing the magnitude of the cross-covariance term in (3). 
The TE of a fund, at any given time, $t$, is the sum of the individual returns of each of its composite stocks weighted by the difference in the proportional holdings between the fund and the index:

$$
\mathrm{TE}_{\mathrm{t}}=\sum_{\mathrm{i}}\left(\mathrm{w}_{\mathrm{i}, \mathrm{t}}-\mathrm{x}_{\mathrm{i}, \mathrm{t}}\right)^{\prime} \mathrm{R}_{\mathrm{i}, \mathrm{t}}
$$

where $w_{i, t}$ and $x_{i, t}$ are the weights of each stock $i$ in the tracker portfolio and the index respectively at time $t$ and $R_{i}$ are the returns of each stock i.

It follows that the serial (over lagged time periods) covariance of a fund's TE's is the sum of the following expression over time and across stocks:

$$
\left(w_{i, t}-x_{i, t}\right)\left(w_{j, t}-x_{j, t}\right) \operatorname{Cov}\left[R_{i, t}, R_{j, t-k}\right]
$$

where $\mathrm{i}$ and $\mathrm{j}$ represent all possible pairs of stocks in the fund and its index.

For stock pairs of similar liquidity, the covariance expression in (5) is expected to be close to zero and of random sign and consequently the contribution to the serial covariance of a fund's TE's for stocks of similar liquidity is expected to be small and unbiased. However, for stock pairs of different liquidity, the contribution to serial covariance is expected to be negative. If a tracker fund is overweight (underweight) in relatively less liquid stocks $\left(\mathrm{W}_{\text {lessliquid }}>\mathrm{x}_{\text {lessliquid }}\right.$ ) and consequently underweight (overweight) in relatively more liquid stocks $\left(\mathrm{w}_{\text {moreliquid }}<\mathrm{x}_{\text {moreliquid }}\right.$ ) then the first two terms in parentheses in (5) will be of opposite sign. Furthermore, the covariance term in (5) is expected to be positive (refer to (3)).

Therefore, the serial covariance (and consequently the serial correlation) of the entire fund's TE's (5) is expected to be negative when an index fund is overweight in either relatively less or relatively more liquid stocks. Furthermore, the greater the difference in the weights of less (or more) liquid stocks between the fund and the index and the higher the frequency of the returns (and the less-price efficient the prices), the more negative the covariance between the TE of stocks of different liquidity in (5) is expected to be.

And so, when a tracker fund is overweight in less liquid stocks, the TE's of the fund are expected to be negatively correlated over time and consequently the usual estimation of TEV is expected to overstate the true TEV.

The following section explores the domestic unit trust industry for evidence of negative serial correlation in the TE's of index-tracking funds.

\section{Analysis of SA tracker funds}

\section{The data}

The South African Unit Trust industry in 2002 had 13 listed domestic index tracker funds: one bond tracker, five JSE All
Share index tracker funds, five JSE ALSI-40 index tracker funds and two JSE Financial and Industrial (FINDI) index tracker funds. For the purpose of this study, only the equity index trackers were considered. The weekly, monthly and quarterly ${ }^{8)}$ returns of the funds that track each of these equity indices and the indices themselves were calculated from December 1995 to April 20029). No income was taken into account on the indices or the index funds and all returns are thus capital growth only ${ }^{10)}$. The returns on the funds were calculated from offer prices only, thus excluding the funds' front-end fees from the calculation as well as all ongoing management and administrative fees.

\section{Test for negative serial correlation}

Weekly, monthly and quarterly TE's were tested for negative serial correlation over several non-overlapping periods. The null and alternate hypotheses are as follows:

$$
\begin{aligned}
& H_{\mathrm{o}}: \rho(-1)=0 \\
& H_{1}: \rho(-1)<0
\end{aligned}
$$

where the correlation $(\rho)$ is measured over a quarterly, monthly or weekly time series. Table 1 summarises the results of the first order serial correlation tests on TE's of all three frequencies.

The results of Table 1 demonstrate that there is significant evidence of negative serial correlation in the TE's of many funds over various periods and frequencies. Given the expectation of decreasing serial correlation with decreasing frequency (refer to "The Rationale Behind TEV Bias"), it is noteworthy that many of the low frequency (quarterly and monthly) data series here exhibit evidence of negative serial correlation.

The fact that these low frequency TE's also display negative correlations means that a monthly or quarterly estimation of TEV cannot be expected to be unbiased. Without an unbiased estimation with which to compare, it is difficult to measure the extent of the bias in TEV estimation over higher frequencies.

Nevertheless, the evidence of negative serial correlation warrants the use of an adjustment to the estimation of TEV. The following section analyses the effect of the LoMacKinlay adjustment for serial correlation on TEV estimation.

\footnotetext{
${ }^{8)}$ In the context of this analysis, 'monthly' means 4-weekly and 'quarterly' means 12 -weekly.

${ }^{9}$ Source of Unit Trust data: Micropal. Source of Index data: Bloomberg.

${ }^{10}$ Dividend income is distributed external to the unit trust fund (refer to regulation 17 of the Unit Trusts Control Act No 54 of 1981) and is not taken into consideration when calculating a unit price for these funds. It can be argued that Tracker funds are mandated to track the capital growth of the index and not the total return. Furthermore, dividend income is typically lumpy and can distort a time series analysis of returns.
} 
Table 1: Serial Correlation $(\mathrm{lag}=1)$ of each Fund's TE against its Benchmark for non-overlapping periods

\begin{tabular}{|c|c|c|c|c|c|c|}
\hline Weekly Serial Correlation & 50 Weeks & 50 Weeks & 50 Weeks & 50 Weeks & 50 Weeks & 50 Weeks \\
\hline Period beginning... & 20-Apr-01 & 05-Мау-00 & 21-Мay-99 & 05-Jun-98 & 20-Jun-97 & 05-Jul-96 \\
\hline \multicolumn{7}{|l|}{ South Africa JSE All Share * } \\
\hline FT NIB Quants Core Equity & 0,06 & $-0,12$ & & & \multirow{3}{*}{$-0,26^{* *}$} & \multirow{5}{*}{$\begin{array}{r}-0,16 \\
0,11\end{array}$} \\
\hline Gryphon Imp SA Tracker & 0,05 & $-0,24 * *$ & $-0,41 * *$ & $-0,16$ & & \\
\hline Sanlam Index & 0,05 & $-0,17$ & 0,15 & $-0,2 *$ & & \\
\hline Investec Index R & $-0,02$ & $-0,02$ & $-0,23 * *$ & 0,23 & $-0,07$ & \\
\hline Standard Bk Index R & $-0,13$ & 0,10 & 0,27 & 0,22 & 0,16 & \\
\hline \multicolumn{7}{|l|}{ South Africa JSE ALSI 40} \\
\hline Coronation ALSI 40 Tracker & $-0,04$ & 0,08 & $-0,39 * *$ & $-0,06$ & \multirow[b]{5}{*}{$-0,2 *$} & \multirow[b]{5}{*}{$-0,3 * *$} \\
\hline Liberty ALSI 40 B1 & $-0,04$ & $-0,17$ & & & & \\
\hline Old Mutual ALSI 40 A & $-0,48 * *$ & & & & & \\
\hline Old Mutual ALSI 40 B1 & $-0,47 * *$ & & & & & \\
\hline RMB Top 40 Index & $-0,08$ & $-0,02$ & $-0,47 * *$ & $-0,19 *$ & & \\
\hline \multicolumn{7}{|l|}{ South Africa JSE FINDI } \\
\hline ABSA Fincl \& Industrial Index & $-0,40 * *$ & $-0,36^{* *}$ & $-0,50 * *$ & 0,25 & & \\
\hline Brait FINDI & $-0,23 *$ & 0,02 & 0,01 & 0,14 & & \\
\hline Monthly Serial Correlation & 25 Months & 25 Months & 25 Months & Quarterly & 12 Quarters & 12 Quarters \\
\hline Period beginning... & 26-Мay-00 & 26-Jun-98 & 26-Jul-96 & & 17-Sep-99 & 13-Dec-96 \\
\hline \multicolumn{7}{|l|}{ South Africa JSE All Share * } \\
\hline FT NIB Quants Core Equity & $-0,04$ & & & & & \\
\hline Gryphon Imp SA Tracker & 0,08 & $-0,35^{* *}$ & & & 0,15 & \\
\hline Sanlam Index & $-0,12$ & 0,41 & & & $-0,46^{*}$ & \\
\hline Investec Index R & $-0,09$ & $-0,14$ & $-0,35^{* *}$ & & $-0,08$ & $-0,09$ \\
\hline Standard Bk Index R & $-0,28 *$ & $-0,42 * *$ & 0,06 & & $-0,69 * *$ & $-0,44^{*}$ \\
\hline \multicolumn{7}{|l|}{ South Africa JSE ALSI 40} \\
\hline Coronation ALSI 40 Tracker & $-0,12$ & $-0,19$ & & & $-0,32$ & \\
\hline Liberty ALSI 40 B1 & $-0,23$ & & & & & \\
\hline \multicolumn{7}{|l|}{ Old Mutual ALSI 40 A } \\
\hline \multicolumn{7}{|l|}{ Old Mutual ALSI 40 B1 } \\
\hline RMB Top 40 Index & $-0,36 * *$ & $-0,34^{*}$ & $-0,01$ & & $-0,64 * *$ & $-0,27$ \\
\hline \multicolumn{7}{|l|}{ South Africa JSE FINDI } \\
\hline ABSA Fincl \& Industrial Index & $-0,27^{*}$ & $-0,14$ & & & $-0,52 *$ & \\
\hline Brait FINDI & 0,40 & 0,09 & & & 0,27 & \\
\hline
\end{tabular}

$*$ and $* *$ indicate significance at the $10 \%$ and $5 \%$ levels respectively.

\section{Adjusted TEV measurement}

\section{Lo - MacKinlay adjustment}

Lo and MacKinlay (1988) show that the ratio of the variance calculated over low frequency data to the variance calculated over high frequency data is related as follows:

$$
\frac{\mathrm{TEV}_{\mathrm{n}}}{\mathrm{TEV}_{1}} \approx 1+\frac{2(\mathrm{n}-1)}{\mathrm{n}} \rho(1)+\frac{2(\mathrm{n}-2)}{\mathrm{n}} \rho(2)+\ldots+\frac{2}{\mathrm{n}} \rho(\mathrm{n}-1) \ldots
$$

where

$\mathrm{TEV}_{\mathrm{n}}$ and $\mathrm{TEV}_{1}$ are the annualised variance of an $\mathrm{n}$ period series (e.g. 4-weekly) and a single period series (e.g. weekly) intervals respectively, and

$\rho(j)$ is the $j^{\text {th }}$ order serial correlation coefficient for the single period TE series.

Clearly, if the single period series is not serially correlated, all the correlation terms in (6) are zero and the ratio of variances is simply one. Furthermore, if the $\mathrm{n}$ period series is unbiased, the equality in (6) can be used to remove bias from the single period estimation of TEV.

As mentioned earlier, on account of negative serial correlation in the monthly and quarterly TE series and the consequent bias in TEV estimates based on these low frequency series, there is no unbiased estimator with which to compare a biased estimate and consequently no way in which to test the efficacy of the Lo-MacKinlay adjustment 
in removing bias in this environment. It is nevertheless of interest to examine the extent of the adjustment for serial correlation that is made to TEV estimates when the LoMacKinlay adjustment is applied to domestic index funds. The following section documents the size of the LoMacKinlay adjustments to weekly annualised estimates of TE standard deviation.

\section{Effect of the Lo-MacKinlay Adjustment on SA funds}

Figure 1 illustrates the size of the Lo-MacKinlay adjustment to annualised TE standard deviation estimates measured over six (where available) non-overlapping, 50-week periods. Each vertical segment of Figure 1 represents these six periods for a different fund. The annualised standard deviation estimates for each period and fund are plotted as two corresponding points, one representing the estimate before adjustment and one after the adjustment and thus the vertical distance between each pair of points represents the size of the adjustment. The funds and periods correspond to those in Table 1. (A similar chart illustrating the adjustment to monthly TE standard deviation estimates can be found in the Appendix -Figure 2).

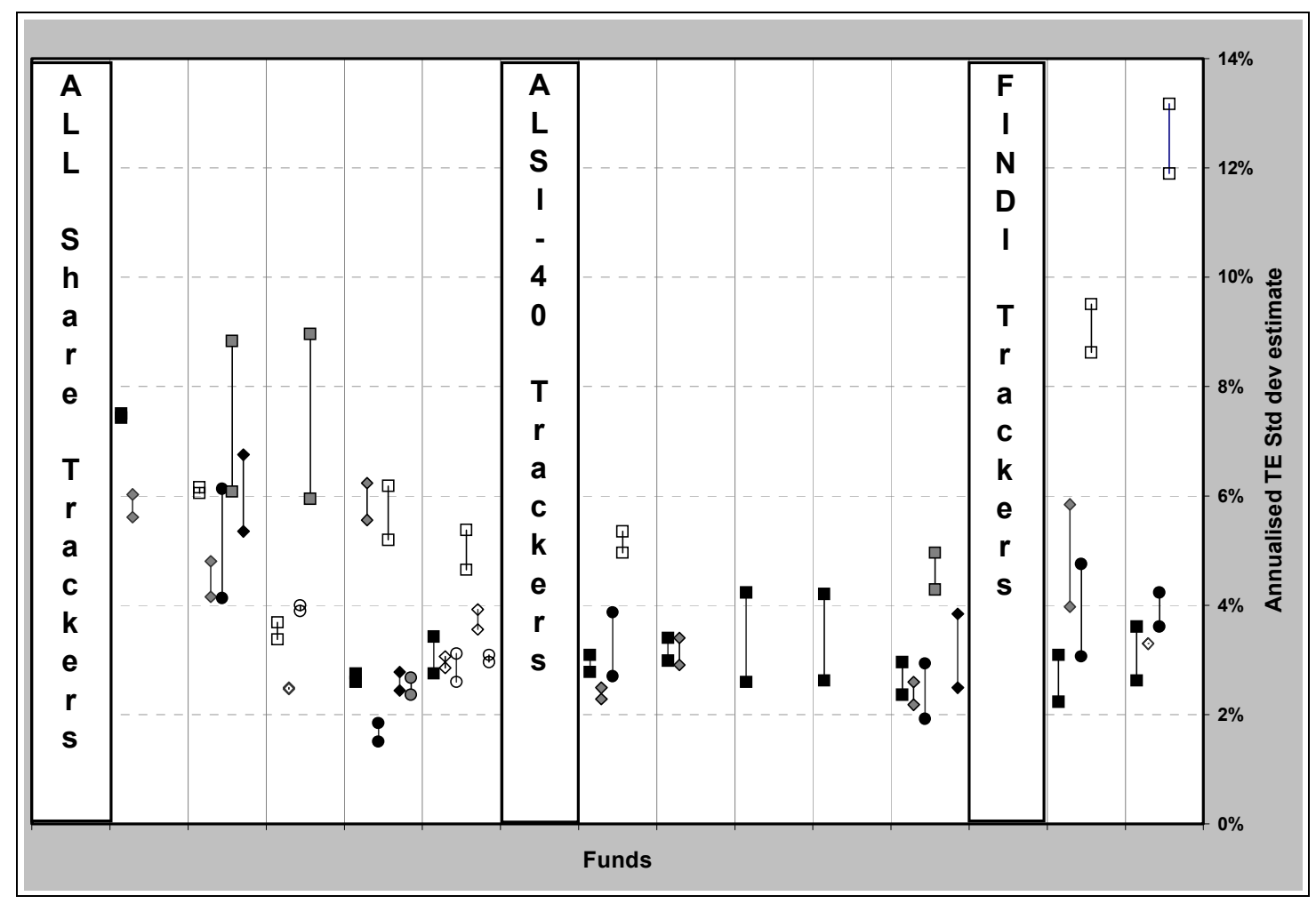

Figure 1: The Lo-MacKinlay Adjustment of weekly annualised Estimates of TE standard deviation for nonoverlapping 50 week periods.

Except for those estimates depicted by unshaded shapes, all the adjustments shown in Figure 1 were downwards (i.e. the estimate which is adjusted for serial correlation is smaller than the unadjusted estimate, as expected). The average downward adjustment was $0.95 \%$ and some of the downward adjustments were as large as $1.5 \%$ to $3 \%$. An overestimation error of active risk to the order of $1 \%$ is considerable, particularly amongst funds for whom the target active risk is close to zero.

Most of the larger adjustments applied to funds with the largest unadjusted TE standard deviations. In most cases, the adjustments brought these larger estimates back into the $2 \%$ to $5 \%$ range thus making their active risk more comparable to their index-tracking peers who were less affected by serial correlation in their TE's. In the highly competitive retail fund management environment, riskadjusted performance is often assessed relative to a peer group. Consequently, if certain funds' active risk is overestimated more than others, their comparative performance rankings will be unfairly penalised unless an estimation adjustment such as this one is made.

\section{Conclusions}

In this article the evidence of serial correlation and its consequent impact on TEV estimation was examined on domestically listed index tracking mutual funds. The analysis shows substantial evidence of negative serial correlation in weekly as well as monthly and quarterly TE's of index funds relative to their respective indices. Consequently the estimates of TEV are upwardly biased and active risk is consequently most likely to be overestimated. 
An adjustment such as the Lo-MacKinlay adjustment can be used to adjust for some of this bias. The success of the LoMacKinlay adjustment cannot be effectively determined unless an unbiased estimation of a fund's TEV is available for comparison. However, adjusting for serial correlation in this way can substantially reduce the estimation of active risk in many cases, particularly for estimates made using high frequency data.

TE measurements should be examined for negative serial correlation before estimates of TEV are made. If serial correlation is detected, estimates of TEV should either be made from lower frequency return measurements with less or no serial correlation, if they are available, or an adjustment technique such as the Lo-MacKinlay adjustment should be used to adjust for positive bias.

\section{References}

Admati, A.R. \& Pfleiderer, P. 1997. 'Does it all add up? Benchmarks and the compensation of active portfolio managers' Journal of Business, 70(3):323-350.

Bradfield, D.J. \& Ardington, C.S. 1997. 'A note on the riskiness of long term investment on the JSE', Journal for Studies in Economics and Econometrics, 21(3):67-77.

Connor, G. 1995. 'Cash management for index tracking', Financial Analysts Journal, 51(6):75-80.

Grinold, R.C. \& Kahn, R.N. 2000. Active portfolio management: A quantitative approach for producing superior returns and controlling risk. Second Edition. USA: McGraw-Hill.

Lo, A. W. \& MacKinlay, A.C. 1988. 'Stock prices do not follow random walks: Evidence from a simple specification test', Review of Financial Studies, 1:41-66.

Pope, P. F. \& Yadav, P.K. 1994. 'Discovering errors in tracking error', The Journal of Portfolio Management, 20(2):27-32.

Roll, R. 1992. 'A mean/variance analysis of tracking error', The Journal of Portfolio Management, 18(4):13-22.

Wortzel, K.J., Vassiadou-Zeniou, C. \& Zenios, S. A, 1994, 'Integrated simulation and optimisation models for tracking indices of fixed-income securities', Operations Research, 42(2):223-233. 


\section{Appendix}

Table 2: Serial Correlation $(\mathrm{lag}=2)$ of each Fund's TE against its Benchmark for non-overlapping periods

\begin{tabular}{|c|c|c|c|c|c|c|}
\hline Weekly Serial Correlation & 50 Weeks & 50 Weeks & 50 Weeks & 50 Weeks & 50 Weeks & 50 Weeks \\
\hline $\begin{array}{l}\text { Period beginning... } \\
\text { South Africa JSE All Share * }\end{array}$ & 20-Apr-01 & 05-May-00 & 21-Мay-99 & 05-Jun-98 & 20-Jun-97 & 05-Jul-96 \\
\hline FT NIB Quants Core Equity & $-0,13$ & 0,16 & & & & \\
\hline Gryphon Imp SA Tracker & $-0,01$ & 0,23 & $-0,01$ & $-0,4 * *$ & 0,03 & \\
\hline Sanlam Index & 0,07 & 0,23 & $-0,11$ & $-0,35 * *$ & & \\
\hline Investec Index R & $-0,11$ & $-0,09$ & $-0,03$ & 0,09 & 0,00 & 0,02 \\
\hline Standard Bk Index R & $-0,04$ & 0,02 & 0,08 & 0,03 & 0,03 & $-0,06$ \\
\hline \multicolumn{7}{|l|}{ South Africa JSE ALSI 40} \\
\hline Coronation ALSI 40 Tracker & $-0,15$ & $-0,17$ & 0,04 & 0,34 & & \\
\hline Liberty ALSI 40 B1 & $-0,19^{*}$ & 0,14 & & & & \\
\hline Old Mutual ALSI 40 A & 0,11 & & & & & \\
\hline Old Mutual ALSI 40 B1 & 0,11 & & & & & \\
\hline RMB Top 40 Index & $-0,22 *$ & $-0,07$ & 0,16 & 0,03 & 0,05 & $-0,25^{* *}$ \\
\hline \multicolumn{7}{|l|}{ South Africa JSE FINDI } \\
\hline ABSA Fincl \& Industrial Index & 0,21 & 0,14 & 0,15 & 0,00 & & \\
\hline$\underline{\text { Brait FINDI }}$ & $-0,04$ & $-0,07$ & $-0,19 *$ & 0,07 & & \\
\hline
\end{tabular}

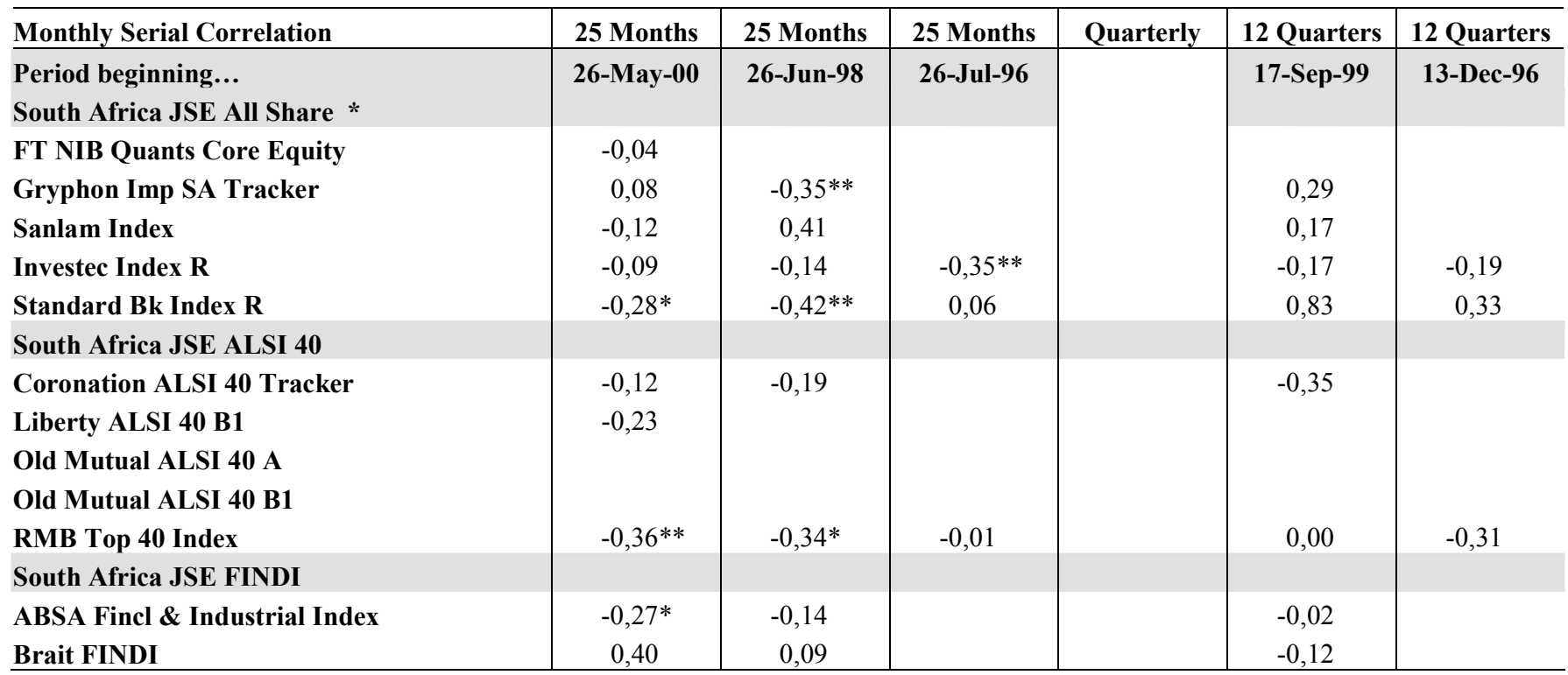

$*$ and $* *$ indicate significance at the $10 \%$ and $5 \%$ levels respectively. 
Table 3: Serial Correlation $(\operatorname{lag}=3$ ) of each Fund's TE against its Benchmark for non-overlapping periods

\begin{tabular}{|c|c|c|c|c|c|c|}
\hline Weekly Serial Correlation & 50 Weeks & 50 Weeks & 50 Weeks & 50 Weeks & 50 Weeks & 50 Weeks \\
\hline Period beginning... & 20-Apr-01 & 05-May-00 & 21-May-99 & 05-Jun-98 & 20-Jun-97 & 05-Jul-96 \\
\hline \multicolumn{7}{|l|}{ South Africa JSE All Share * } \\
\hline FT NIB Quants Core Equity & 0,05 & $-0,22 *$ & & & & \\
\hline Gryphon Imp SA Tracker & $-0,05$ & $-0,23 *$ & 0,17 & 0,23 & $-0,04$ & \\
\hline Sanlam Index & 0,10 & 0,09 & $-0,13$ & 0,17 & & \\
\hline Investec Index R & 0,07 & $-0,16$ & 0,07 & $-0,05$ & $-0,28 * *$ & $-0,03$ \\
\hline Standard Bk Index R & $-0,23 *$ & $-0,01$ & $-0,08$ & $-0,04$ & $-0,10$ & $-0,06$ \\
\hline \multicolumn{7}{|l|}{ South Africa JSE ALSI 40} \\
\hline Coronation ALSI 40 Tracker & 0,02 & $-0,2 *$ & 0,06 & $-0,18$ & & \\
\hline Liberty ALSI 40 B1 & 0,03 & $-0,32 * *$ & & & & \\
\hline Old Mutual ALSI 40 A & $-0,02$ & & & & & \\
\hline Old Mutual ALSI 40 B1 & $-0,03$ & & & & & \\
\hline RMB Top 40 Index & $-0,04$ & $-0,39 * *$ & $-0,05$ & 0,15 & $-0,07$ & 0,24 \\
\hline \multicolumn{7}{|l|}{ South Africa JSE FINDI } \\
\hline ABSA Fincl \& Industrial Index & $-0,18$ & $-0,27 * *$ & 0,02 & $-0,33 * *$ & & \\
\hline Brait FINDI & $-0,18$ & 0,08 & $-0,21 *$ & $-0,11$ & & \\
\hline
\end{tabular}

\begin{tabular}{l|c|c|c}
\hline Monthly Serial Correlation & 25 Months & 25 Months & 25 Months \\
\hline Period beginning... & 26-May-00 & 26-Jun-98 & 26-Jul-96 \\
South Africa JSE All Share * & 0,22 & \\
FT NIB Quants Core Equity & 0,00 & 0,05 & \\
Gryphon Imp SA Tracker & $-0,46^{* *}$ & $-0,11$ & \\
Sanlam Index & $-0,02$ & 0,23 & $-0,05$ \\
Investec Index R & $-0,37^{* *}$ & 0,04 & $-0,26$ \\
Standard Bk Index R & & & \\
South Africa JSE ALSI 40 & $-0,05$ & 0,14 & \\
Coronation ALSI 40 Tracker & $-0,07$ & & \\
Liberty ALSI 40 B1 & & & \\
Old Mutual ALSI 40 A & & & \\
Old Mutual ALSI 40 B1 & 0,12 & 0,73 & \\
RMB Top 40 Index & & & \\
South Africa JSE FINDI & 0,10 & 0,29 & \\
ABSA Fincl \& Industrial Index & $-0,13$ & 0,01 & \\
Brait FINDI & & & \\
\hline
\end{tabular}

$*$ and ** indicate significance at the $10 \%$ and $5 \%$ levels respectively. 


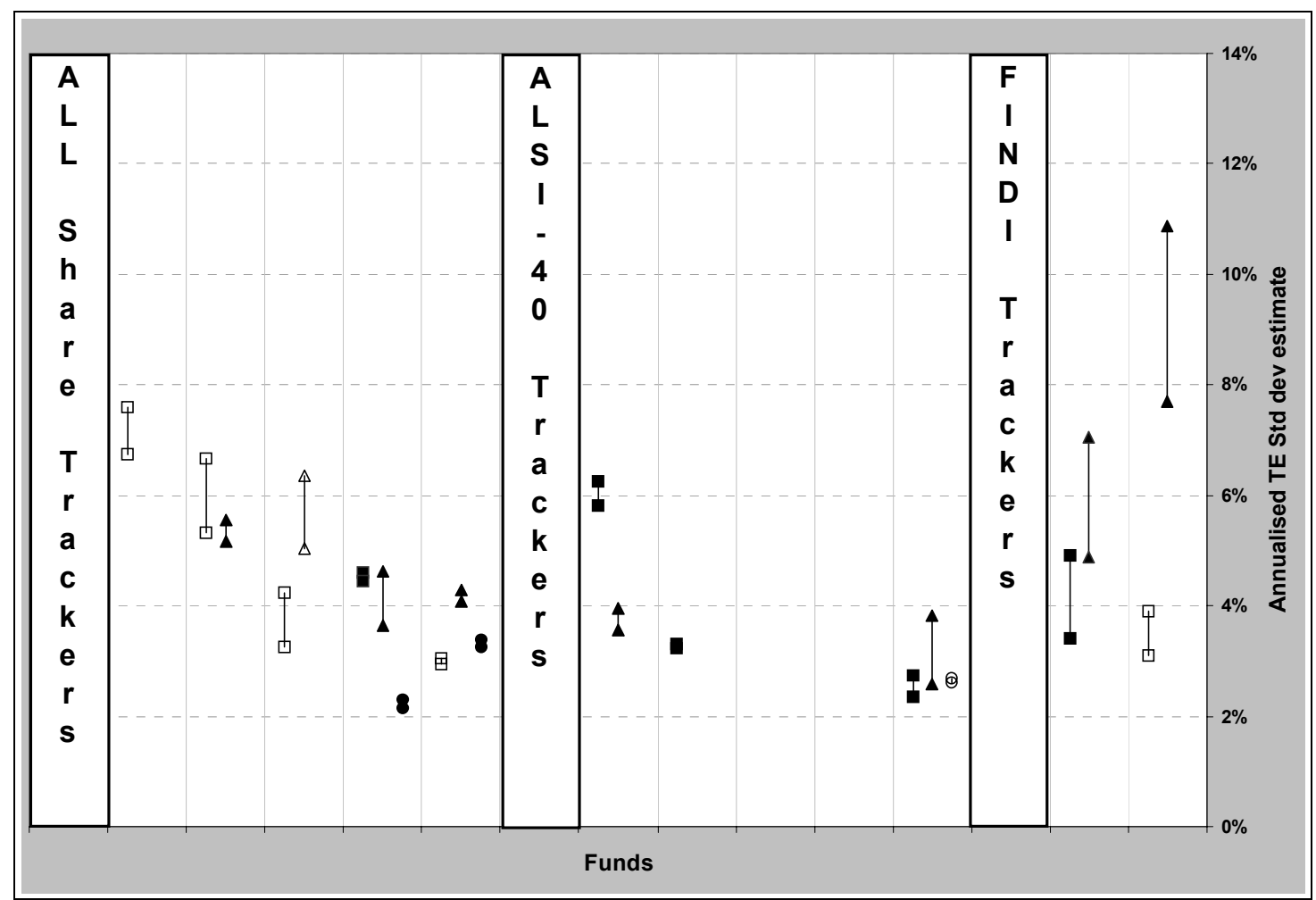

Figure 2: The Lo-MacKinlay Adjustment of Monthly Annualised Estimates of TE Standard Deviation for non-overlapping 25 month periods. 